\title{
Relationships among size, development, and Batrachochytrium dendrobatidis infection in African tadpoles
}

\author{
Kevin G. Smith ${ }^{1,2, *}$, Ché Weldon ${ }^{1}$, Werner Conradie ${ }^{1}$, Louis H. du Preez ${ }^{1}$ \\ ${ }^{1}$ Zoology, School of Environmental Sciences and Development, North-West University, Private Bag x6001, \\ Potchefstroom 2520, South Africa \\ ${ }^{2}$ Present address: Department of Biology, Box 1229, Washington University in St. Louis, 1 Brookings Drive, \\ St. Louis, Missouri 63130, USA
}

\begin{abstract}
The fungal pathogen Batrachochytrium dendrobatidis contributes to the global decline of amphibians. Although mortality from B. dendrobatidis infections occurs primarily in postmetamorphic individuals, infected tadpoles may suffer reduced growth and developmental rates as a result of oral chytridiomycosis, possibly affecting adult fitness. We conducted a field study in which we examined South African tadpoles for oral chytridiomycosis and compared the body sizes of infected and uninfected individuals of 2 species, Heleophryne natalensis and Strongylopus hymenopus. Presence of $B$. dendrobatidis was determined by microscopic inspection of mouthparts. Infection prevalence was high in both species, 62.5 and $38.6 \%$, respectively, and infected individuals were significantly larger in both species. The inclusion of developmental stage in the analysis of $S$. hymenopus body size eliminated the relationship between body size and infection status, suggesting that differences in body size were not due to differences in growth, but to differences in developmental stage of infected larvae. These results suggest that larvae at more advanced developmental stages are more likely to be infected with $B$. dendrobatidis and that infection in larval amphibians may be dependent on time or developmental status of larvae. Contrary to the results of past studies, there was no evidence that oral chytridiomycosis resulted in decreased growth of tadpoles, despite the occurrence of oral abnormalities in infected individuals of 1 species. Because tadpole performance can subsequently affect the health of anuran populations and because tadpoles can act as reservoirs of infection, the study of $B$. dendrobatidis in larval amphibians is important to understanding the effects of this emerging disease.
\end{abstract}

KEY WORDS: Oral chytridiomycosis · Amphibian chytrid $\cdot$ Life history $\cdot$ Growth $\cdot$ Development · Amphibian conservation

\section{INTRODUCTION}

Amphibians have recently experienced high rates of extinction, and a large proportion of taxa are threatened (Stuart et al. 2004, but see Pimenta et al. 2005). Of the many potential causes of amphibian declines, emerging infectious diseases are increasingly recognized as a contributing factor (Daszak et al. 2003). One disease, chytridiomycosis caused by the fungal pathogen Batrachochytrium dendrobatidis, can cause high levels of mortality and has contributed to the decline of amphibians in the Australian and American tropics (Berger et al. 1998), Europe (Bosch et al. 2001), and North America (Muths et al. 2003). Although there is some uncertainty about the contribution of chytridiomycosis to amphibian declines and extinctions (McCallum 2005), compelling correlative evidence of a strong association between chytridiomycosis and amphibian extinctions has strengthened the evidence for $B$. dendrobatidis as an agent of amphibian declines (Lips et al. 2006, Pounds et al. 2006).

Batrachochytrium dendrobatidis infects the keratinized cutaneous epithelium of adult amphibians and keratinized mouthparts of anuran larvae. Although 
mortality occurs overwhelmingly in postmetamorphic individuals, sometimes resulting in drastic declines of adult anurans (Berger et al. 1999), infections in tadpoles are also of ecological significance. Infected tadpoles may act as reservoirs of $B$. dendrobatidis, passing chytridiomycosis to postmetamorphic individuals and allowing outbreaks to persist, especially in species with long developmental periods (Rachowicz \& Vredenburg 2004, McCallum 2005). Experimental studies also suggest that oral chytridiomycosis affects the performance of tadpoles, resulting in decreased growth or inhibited competitive ability of tadpoles infected as a cohort, perhaps as a result of damage to mouthparts, resulting in decreased feeding efficiency (Parris \& Cornelius 2004). Oral chytridiomycosis may therefore affect population viability, even in the absence of significant postmetamorphic mortality, since reductions in tadpole growth and developmental rates may reduce the fitness of adults (Berven 1981, Smith 1987, but see Boone 2005).

Despite the potential importance of larval chytridiomycosis to the population-level effects of Batrachochytrium dendrobatidis, very little is known about the effects of chytrid infection in anuran larvae in the wild. In particular, information on the relationship between infection status and tadpole life-history traits is lacking, but could provide information on the effects of chytridiomycosis on tadpole growth and development and on ontogenetic variation in the disease susceptibility of anuran larvae. Such information could also help identify important reservoir species and life stages that contribute to the effects of $B$. dendrobatidis.

To address these topics we conducted field surveys of Batrachochytrium dendrobatidis infection in tadpoles of the Drakensberg Mountains of South Africa and Lesotho. Here, we report on patterns of infection with respect to body size and developmental stage in the larvae of 2 species: the Natal ghost frog Heleophryne natalensis (Heleophrynidae) and the berg stream frog Strongylopus hymenopus (Pyxicephalidae).

\section{MATERIALS AND METHODS}

Study area, site selection, and species. We conducted surveys in the northern Drakensberg region along the northeastern border of Lesotho and the borders of the Free State and KwaZulu-Natal provinces of South Africa. We selected sites as part of a larger longterm amphibian disease monitoring program in southern Africa. Sites are individual sections of mountain streams, marshes, or pools. We eliminated from this analysis sites in which Batrachochytrium dendrobatidis was not detected. The resulting subset of sites includes 32 locations ranging in elevation from 1505 to $3069 \mathrm{~m}$ above sea level (ASL) and between 28.6547 and $28.9561^{\circ} \mathrm{S}$ and 28.7041 and $28.9561^{\circ} \mathrm{E}$.

Four species were documented in at least 1 location within the study area: Heleophryne natalensis and Strongylopus hymenopus, the clicking stream frog Strongylopus grayii (Pyxicephalidae), and the largemouthed stream frog Amietia vertebralis (Pyxicephalidae). Although Batrachochytrium dendrobatidis is present in some populations of the latter 2 species, we did not include them in our analyses owing to prohibitively small sample sizes. Both $H$. natalensis and S. hymenopus are endemic to southern Africa, the latter occurring only in the Drakensberg region of South Africa and Lesotho. The larvae of both species occur almost exclusively in mountain streams: $S$. hymenopus in high-altitude (1800 to $>3000 \mathrm{~m} \mathrm{ASL)} \mathrm{streams} \mathrm{and} H$. natalensis in fast-flowing streams $>580 \mathrm{~m}$ ASL in forested habitats or rocky ravines (Minter et al. 2004). The larvae of both species are present throughout the year.

Survey methods and data collection. Visits were made to survey sites during daylight in January, April, May, July, and September 2006. Strongylopus hymenopus tadpoles were collected, sacrificed, and stored in $70 \%$ ethanol for laboratory screening for the presence of oral Batrachochytrium dendrobatidis infection and were screened within $1 \mathrm{wk}$ of collection. Tadpoles of Heleophryne natalensis were screened immediately after capture in the field and released. From each individual we collected data on body length $(\mathrm{mm})$ (Altig \& McDiarmid 1999) and developmental stage (Gosner 1960). Developmental stage could not be determined reliably for all $H$. natalensis since key diagnostic features of the hind limbs are obscured until late in development.

For Strongylopus hymenopus tadpoles, we removed and visually inspected the lower oral disc, including the lower keratodonts and rostrodont. We first visually inspected mouthparts for gross abnormalities using a dissecting microscope at $10 \times$ magnification and recorded instances of malformations or loss of keratinized mouthparts. We then made whole-mount microscopic preparations by mounting the oral disc in a drop of water on a microscope slide and covering with a coverslip. We examined the mouthparts at $100 \times$ and $400 \times$ magnification using a standard compound microscope. Batrachochytrium dendrobatidis was identified by the presence of spheroid, walled, septate sporangia, typically occurring in clusters and sometimes containing zoospores (Berger et al. 1998).

Heleophryne natalensis tadpoles were screened in the field using a $20 \times$ hand lens. When infected with Batrachochytrium dendrobatidis, this species exhibits clearly defined areas of brown pigmentation at infec- 


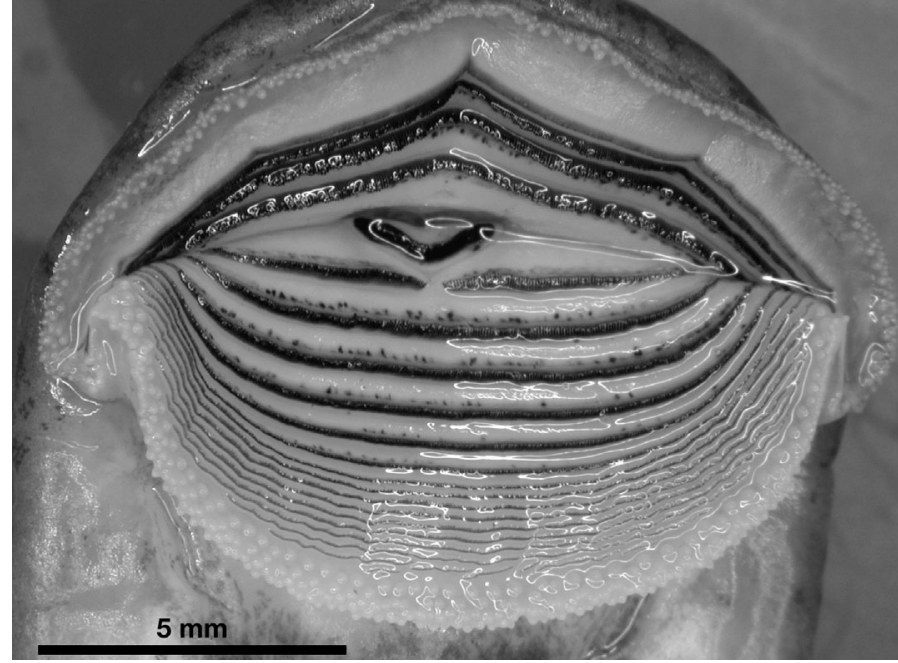

Fig. 1. Heleophryne natalensis. Photomicrograph of the larval mouthparts showing the pigmented infection foci of an individual infected with Batrachochytrium dendrobatidis. This individual is typical of infected individuals of this species from southern Africa

tion foci (Fig. 1). The identification of brown infection foci using a hand lens is a highly reliable indicator of oral chytridiomycosis in this species. We conducted a reliability study of this method on $74 \mathrm{H}$. natalensis tadpoles and found a strong relationship between detection of $B$. dendrobatidis and the presence of pigmented infection foci $\left(\chi^{2}=66.15\right.$, $\left.\mathrm{df}=1, \mathrm{p}<0.000001\right)$. This study yielded a Kappa reliability test value of 0.94 , indicating excellent agreement between the 2 methods of identifying oral chytridiomycosis (Hintze 2001).

Hypotheses and data analysis. Our first objective was to test the null prediction that infected and uninfected individuals do not differ significantly in body size. If oral chytridiomycosis reduces the foraging efficiency of tadpoles, then infected individuals should have smaller mean body lengths than uninfected individuals. We used Student's $t$-test for Strongylopus hymenopus and the Aspin-Welch $t$-test (unequal variance) for Heleophryne natalensis to evaluate this hypothesis at $\alpha=0.05$.

Our second objective was to determine if differences in body size among tadpoles, if present, were the result of differences in growth rate due to Batrachochytrium dendrobatidis or of differences in the demography of infection (i.e. infection is only found in young individuals or, conversely, does not occur until later developmental stages). To address this objective we tested the null hypothesis that differences in body size could not also be explained by differences in Gosner developmental stage. For example, if infected tadpoles are smaller, is the size difference the result of reduced growth rate or because fewer individuals are infected as development progresses? We tested this hypothesis by controlling for the influence of developmental stage by incorporating this factor as a covariate in an analysis of covariance (ANCOVA) on body length. This analysis effectively tests for the effect of $B$. dendrobatidis infection on body length within tadpoles of similar developmental stages. A lack of significant differences in body length would indicate that infected and uninfected tadpoles at similar developmental stages show no difference in body size. Such a result would allow us to reject the hypothesis that differences in body size are due to differences in growth rate, suggesting that infection is constrained to tadpoles of certain developmental stages. In contrast, significant differences in body length among infected and uninfected tadpoles of similar developmental stage would suggest that infection status affects tadpole growth rate. We restricted this analysis to data from Strongylopus hymenopus, the only species for which we had reliable data on developmental stage. For S. hymenopus we also conducted a linear regression of infection prevalence against Gosner stage to determine the strength of the relationship between these 2 variables.

Finally, we also aimed to determine if the body size-infection status relationship changed with survey month by testing for an interaction between survey month and infection status in a 2-factor ANOVA. This analysis evaluates whether the body size-infection status relationship was simply an artifact of when surveys took place. The presence of an interaction would suggest that the body size-infection status relationship is affected by timing and that differences in body size are the result of tadpole cohorts being infected at different times.

To prevent error rate inflation as a result of pseudoreplication, we calculated mean values of all measures for each species from each survey and used these values in all statistical analyses.

\section{RESULTS}

\section{Survey results}

Heleophryne natalensis and Strongylopus hymenopus tadpoles were found and collected at 19 and 13 sites, respectively. The 2 species were never found syntopically in the study area and, hence, were never collected from the same site. Screening of tadpole mouthparts indicated that individuals of both species were frequently infected with Batrachochytrium dendrobatidis. Across all surveys the prevalence of oral 
chytridiomycosis was $62.5 \%$ (range: 0 to $100 \%$ ) for $H$. natalensis and $38.6 \%$ (range: 0 to $100 \%$ ) for $S$. hymenopus. Mouthpart damage was observed in 5 H. natalensis $(1.7 \%$ of total), all of which were diagnosed with oral chytridiomycosis. Forty-one $S$. hymenopus were recorded with damaged mouthparts (16.0\% of total), of which 39 were diagnosed with oral B. dendrobatidis. There was no evidence of differences in either body length or developmental stage of infected $S$. hymenopus as a result of mouthpart damage (body length: Student's $t=-0.50, \mathrm{p}=0.62, \mathrm{n}_{1}=58$, $\mathrm{n}_{2}=39$; Gosner stage: Student's $t=-0.88, \mathrm{p}=0.38, \mathrm{n}_{1}=$ $58, n_{2}=39$ ), where $n_{1}$ is the sample size of uninfected and $\mathrm{n}_{2}$ the sample size of infected individuals.

\section{Differences in body size and development}

For both species, tadpole body size differed significantly between individuals with and without oral Batrachochytrium dendrobatidis infections (Fig. 2).

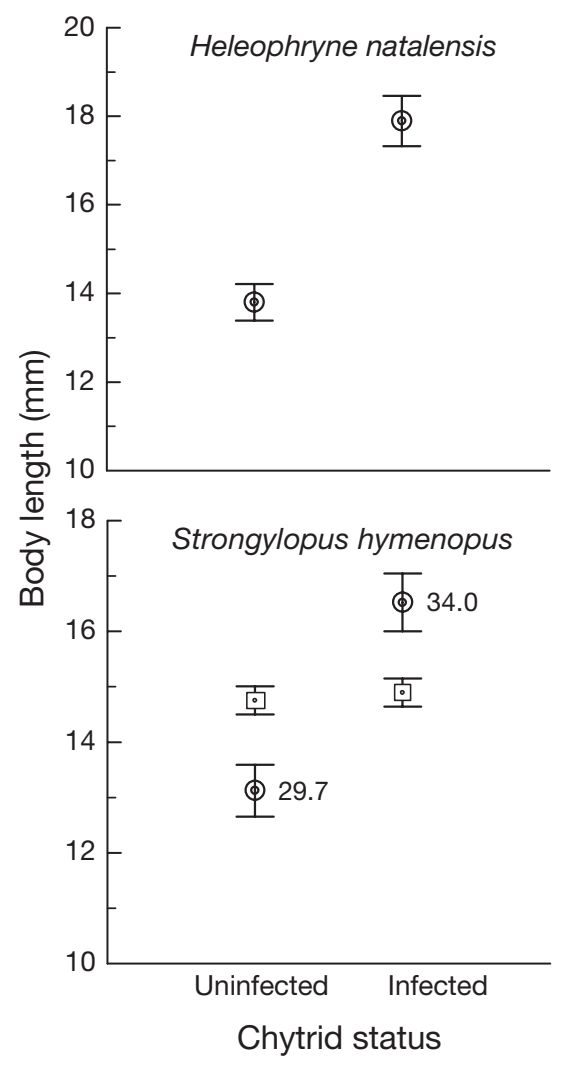

Fig. 2. Heleophryne natalensis, Strongylopus hymenopus. Mean body length of tadpoles with and without oral Batrachochytrium dendrobatidis infection for 2 species collected from the Drakensberg Mountains of South Africa and Lesotho. (O) Body length; ( $\square$ ) body length adjusted for variation in Gosner stage; numerals are mean Gosner stage values for each group. Error bars show $\pm 1 \mathrm{SE}$
Infected individuals of Heleophryne natalensis (AspinWelch $t=-5.84, \mathrm{p}<0.000001, \mathrm{n}_{1}=33, \mathrm{n}_{2}=36$ ) andStrongylopus hymenopus (Student's $t=-4.85, \mathrm{p}=$ $0.00002, \mathrm{n}_{1}=21, \mathrm{n}_{2}=21$ ) were significantly larger than uninfected conspecifics. Infected $S$. hymenopus larvae were also significantly more developed than were uninfected larvae (Student's $t=-5.39$, p < 0.00001).

When developmental stage was included as a covariate in the analysis of the body size of Strongylopus hymenopus, there was no significant difference in body length between infected and uninfected tadpoles (ANCOVA, covariate [stage]: $F_{1,39}=110.99, \mathrm{p}<$ 0.000001 ; infection: $F_{1,39}=0.09, \mathrm{p}=0.76$ ). Adjusting group means for differences in developmental stage results in statistically indistinguishable body length values for infected and uninfected individuals (Fig. 2).

Proportional prevalence of Batrachochytrium dendrobatidis was significantly and positively related with developmental stage in Strongylopus hymenopus ( $\mathrm{n}=$ 17, $\left.\mathrm{r}^{2}=0.77, \mathrm{p}<0.0001\right)$. Variation in Gosner stage explained $76.8 \%$ of the variation in infection prevalence in this relationship.

There was no evidence for an effect of survey month on the body size-infection status relationship for Heleophryne natalensis (ANOVA, interaction of infection and survey: $\left.F_{2,63}=0.16, \mathrm{p}=0.85\right)$ or Strongylopus hymenopus $\left(F_{3,34}=1.64, \mathrm{p}=0.20\right)$. Within surveys, mean body size of infected tadpoles was always greater than mean size of uninfected tadpoles.

\section{DISCUSSION}

The results of our analyses suggest a strong relationship between Batrachochytrium dendrobatidis infection and larval body size in Heleophryne natalensis and Strongylopus hymenopus. Infected individuals of both species were significantly larger than uninfected individuals. When developmental stage is held constant in the analysis of $S$. hymenopus body size, however, no difference in body size was detected between infected and uninfected tadpoles. In other words, when compared within similar developmental stages, infected and uninfected tadpoles were of similar body size. This suggests that observed differences in tadpole body size in $S$. hymenopus were not the result of changes in growth rate per se, but of different rates of infection across developmental stages, such that larger, more developed tadpoles were more likely to be infected. This conclusion is also supported by the strong positive relationship between infection prevalence and developmental stage. For example, at Gosner Stage 30 only $15.8 \%$ of $S$. hymenopus were infected, while $62.5 \%$ were infected at Stage 35 . 
This positive relationship between Batrachochytrium dendrobatidis prevalence and developmental stage could arise from one or a combination of several mechanisms. First, infection may be dependent on the achievement of a particular level of development. This could be caused by changes in behavior, immunocompetence, or mouthpart morphology of tadpoles during development. Second, the process of becoming clinically infected by $B$. dendrobatidis may be time dependent, such that infections occur only after repeated exposures or are detectable only after the infection has reached a critical magnitude. Experimental studies support time-dependence of $B$. dendrobatidis infection: the transmission of $B$. dendrobatidis may take as long as 2 wk in adult anurans (Nichols et al. 2001) and as long as 7 wk in tadpoles (Rachowicz \& Vredenburg 2004), even when artificially high loads of infective zoospores are used as inocula. Finally, if infected tadpoles suffer reduced foraging efficiencies as a result of oral chytridiomycosis, then the resulting reduction in growth rate may result in accelerated development. Such a developmental acceleration might be predicted based on theories and evidence of the complex dynamics of the tadpole growth-development relationship (e.g. Wilbur \& Collins 1973, Alford \& Harris 1988). The net result of such an effect would be a pattern similar to that observed in this study: infected tadpoles at a more advanced developmental stage than uninfected tadpoles. However, an expected consequence of this reduced growth and accelerated development would be that infected tadpoles would be smaller than uninfected tadpoles at similar developmental stages. The results of our ANCOVA analysis, however, show this pattern did not prevail (Fig. 2).

An additional possible explanation for our results is that Batrachochytrium dendrobatidis infection is dependent on the timing of larval development. This explanation could apply if our sample of tadpoles came from 2 cohorts, an older cohort that was present for an infection event and a younger cohort that was not. However, given that $B$. dendrobatidis can be transmitted among tadpoles (Rachowicz \& Vredenburg 2004), infection of the younger cohort could theoretically have occurred at any time during the course of this study. Variation in unmeasured environmental variables could also result in $B$. dendrobatidis infection occurring more frequently at certain times, for example, during certain seasons. However, our analysis of seasonal effects shows no evidence that the relationship between infection and body size varies with season. This result is consistent with the conclusion that differences in body size among infected and uninfected tadpoles are not artifacts of temporal variation in the presence of $B$. dendrobatidis.
Our results do not support previous experimental observations of reduced growth in Batrachochytrium dendrobatidis-infected tadpoles. These past studies suggest that oral chytridiomycosis significantly reduces larval growth and developmental rates, resulting in smaller body size and sometimes delayed metamorphosis (Parris \& Beaudoin 2004, Parris \& Cornelius 2004). In these studies this effect has been hypothesized to be caused by the disfigurement of mouthparts in B. dendrobatidis-infected individuals, leading to reduced foraging efficiency and growth and developmental rates. We saw no evidence of such an effect in our study, despite a relatively high incidence of oral disfigurement in Strongylopus hymenopus. However, our results do not specifically refute these previous studies, which assessed growth and developmental rates based on data collected at metamorphosis. Since our data were from premetamorphic individuals, it may be that reductions in growth rates occur primarily in the later stages of tadpole development, especially shortly before metamorphosis. However, several studies suggest that developmental rates in late-stage tadpoles are fixed (e.g. Hensley 1993, Leips \& Travis 1994, reviewed in Harris 1999), which may preclude changes in developmental rate as a response to the effects of B. dendrobatidis infection late in the larval period.

Another explanation relates to a recent hypothesis that Batrachochytrium dendrobatidis is endemic to southern Africa and has only recently emerged elsewhere as a result of international trade in infected amphibians (Weldon et al. 2004). Although this hypothesis lacks rigorous support, it is possible that interspecific differences in the response of amphibian larvae to $B$. dendrobatidis are related to the historical presence or absence of this pathogen. In contrast to other regions, the relative rarity of $B$. dendrobatidisassociated die-offs in southern Africa suggests the existence of important regional differences either in the pathogenicity of $B$. dendrobatidis or in the host response to $B$. dendrobatidis infection.

Our findings have important implications for management and disease monitoring in amphibian populations. If Batrachochytrium dendrobatidis infection is not evenly distributed within amphibian populations, then our results should be taken into account when sampling programs are designed. For example, if the goal of a study is to determine if $B$. dendrobatidis is present in a population, then larger more developed individuals should be examined preferentially. In contrast, if the goal is to accurately estimate infection prevalence within a population, then efforts must be made to ensure that sampling is random with respect to disease status and that samples are representative of the size and developmental structure of the population. 
When compared to previous results (Parris \& Beaudoin 2004, Parris \& Cornelius 2004), our study also suggests that the effects of chytridiomycosis vary significantly among amphibian species from diverse geographic regions. This may result from differences in host susceptibility (Blaustein et al. 2005) or pathogenicity of Batrachochytrium dendrobatidis strains (Berger et al. 2005). Conservation recommendations and management actions will ideally be based on population-specific information on the effects of chytridiomycosis on amphibians. As the role played by tadpoles in the persistence and effects of $B$. dendrobatidis outbreaks is largely unknown, additional studies on this topic are needed. In particular, we expect that additional experimental studies on this topic will be especially helpful in understanding the potentially complex relationships between infection, tadpole growth and development, and the population-level effects of $B$. dendrobatidis.

Acknowledgements. We thank M. J. Cunningham for suggesting that we conduct surveys in part of the study area and for assistance in planning and executing field work. Ezemvelo/KwaZulu-Natal Wildlife provided logistical support and permission to work in Royal Natal National Park, and we especially thank S. Richert, E. Goosen, S. Krueger, and I. Rushworth for their support. This project was supported by the National Research Foundation of South Africa and the Declining Amphibian Populations Task Force. This research was conducted in accordance with all local laws and regulations and with North-West University animal use and care guidelines.

\section{LITERATURE CITED}

Alford RA, Harris RN (1988) Effects of larval growth history on anuran metamorphosis. Am Nat 131:91-106

Altig R, McDiarmid RW (1999) Body plan: development and morphology. In: McDiarmid RW, Altig R (eds) Tadpoles: the biology of anuran larvae. University of Chicago Press, p 24-51

Berger L, Speare R, Daszak P, Green DE and 10 others (1998) Chytridiomycosis causes amphibian mortality associated with population declines in the rain forests of Australia and Central America. Proc Natl Acad Sci USA 95: 9031-9036

Berger L, Speare R, Hyatt AD (1999) Chytrid fungi and amphibian declines: overview, implications and future directions. In: Campbell A (ed) Declines and disappearances of Australian frogs. Environment Australia, Canberra, p 23-33

Berger L, Marantelli G, Skerratt LF, Speare R (2005) Virulence of the amphibian chytrid fungus Batrachochytrium dendrobatidis varies with the strain. Dis Aquat Org 68: 47-50

Berven KA (1981) Mate choice in the wood frog, Rana sylvatica. Evolution 35:707-722

Blaustein AR, Romansic JM, Scheessele EA, Han BA, Pessier AP, Longcore JE (2005) Interspecific variation in susceptibility of frog tadpoles to the pathogenic fungus Batrachochytrium dendrobatidis. Conserv Biol 19:1460-1468

Boone MD (2005) Juvenile frogs compensate for small metamorph size with terrestrial growth: overcoming the effects of larval density and insecticide exposure. J Herpetol 39: $416-423$
Bosch J, Martinez-Solano I, Garcia-Paris M (2001) Evidence of a chytrid fungus infection involved in the decline of the common midwife toad (Alytes obstetricans) in protected areas of central Spain. Biol Conserv 97:331-337

Daszak P, Cunningham AA, Hyatt AD (2003) Infectious disease and amphibian population declines. Divers Distrib 9: $141-150$

Gosner KL (1960) A simplified table for staging anuran embryos and larvae with notes on identification. Herpetologica 16:183-190

Harris RN (1999) The anuran tadpole: evolution and maintenance. In: McDiarmid RW, Altig R (eds) Tadpoles: the biology of anuran larvae. University of Chicago Press, p 279-294

Hensley FR (1993) Ontogenetic loss of phenotypic plasticity of age at metamorphosis in tadpoles. Ecology 74:2405-2412

Hintze J (2001) Number cruncher statistical systems. Available at www.ncss.com

Leips J, Travis J (1994) Metamorphic responses to changing food levels in two species of hylid frogs. Ecology 75 : 1345-1356

Lips KR, Brem F, Brenes R, Reeve JD and 6 others (2006) Emerging infectious disease and the loss of biodiversity in a neotropical amphibian community. Proc Natl Acad Sci USA 103:3165-3170

McCallum H (2005) Inconclusiveness of chytridiomycosis as the agent in widespread frog declines. Conserv Biol 19: 1421-1430

Minter LR, Burger M, Harrison JA, Braack HH, Bishop PJ, Kloepfer D (eds) (2004) Atlas and red data book of the frogs of South Africa, Lesotho, and Swaziland, SI/MAB Series No. 9. Smithsonian Institution/Avian Demography Unit, Rondebosch

Muths E, Corn PS, Pessier AP, Green DE (2003) Evidence for disease-related amphibian decline in Colorado. Biol Conserv 110:357-365

Nichols DK, Lamirande EW, Pessier AP, Longcore JE (2001) Experimental transmission of cutaneous chytridiomycosis in dendrobatid frogs. J Wildl Dis 37:1-11

Parris MJ, Beaudoin JG (2004) Chytridiomycosis impacts predator-prey interactions in larval amphibian communities. Oecologia 140:626-632

Parris MJ, Cornelius TO (2004) Fungal pathogen causes competitive and developmental stress in larval amphibian communities. Ecology 85:3385-3395

Pimenta BVS, Haddad CFB, Nascimento LB, Cruz CAG, Pombal JP Jr (2005) Comment on 'status and trends of amphibian declines and extinctions worldwide.' Science 309: 1999b, doi:10.1126/science.1112996, Sep 23, 2005

Pounds JA, Bustamante RM, Coloma LA, Consuegra JA and 10 others (2006) Widespread amphibian extinctions from epidemic disease driven by global warming. Nature 439:161-167

Rachowicz LJ, Vredenburg VT (2004) Transmission of Batrachochytrium dendrobatidis within and between amphibian life stages. Dis Aquat Org 61:75-83

Smith DC (1987) Adult recruitment in chorus frogs: effects of size and date at metamorphosis. Ecology 68:344-350

Stuart SN, Chanson JS, Cox NA, Young BE, Rodrigues ASL, Fischman DL, Waller RW (2004) Status and trends of amphibian declines and extinctions worldwide. Science 306:1783-1786

Weldon C, du Preez LH, Hyatt AD, Muller R, Speare R (2004) Origin of the amphibian chytrid fungus. Emerg Infect Dis 10:2100-2105

Wilbur HM, Collins JP (1973) Nonnormal distributions of competitive ability reflect selection for facultative metamorphosis. Science 182:1305-1314 